\title{
The effect of geometry on mechanical properties of Ti6Al4V ELI scaffolds manufactured using additive manufacturing technology
}

\author{
Patrycja Szymczyk $^{1}$ (D) $\cdot$ Viktoria Hoppe $^{1} \cdot$ Grzegorz Ziółkowski $^{1} \cdot$ Michał Smolnicki $^{2} \cdot$ Marcin Madeja $^{1}$
}

Received: 20 January 2020 / Revised: 20 January 2020 / Accepted: 27 January 2020 / Published online: 13 February 2020

(c) The Author(s) 2020

\begin{abstract}
Owing to the possibility of direct processing of CAD models into three-dimensional objects, additive manufacturing (AM) is widely used in the production of individualized bone scaffolds that can lead to perfect restoration of anatomical structures of missing bone tissues. In this work, one of the AM technologies was applied, referred to as Electron Beam Melting (EBM), using Ti6Al4V ELI alloy to produce open-cell structures. Scaffold architecture influences its mechanical properties and is important from the point of view of biological considerations. To optimize mechanical properties, designed geometries were subjected to Finite Element Method analysis and experimental static compression tests. Also, geometric $\mathrm{CT}$ analysis of manufactured scaffolds was carried out (geometry deviations up to $\pm 300 \mu \mathrm{m}$ ). Obtained results have shown that AM can be used to produce Ti6Al4V ELI alloy scaffolds displaying mechanical parameters similar to those of bone tissue $(E=0.45-2.88 \mathrm{MPa})$. The EBM process affects the microstructure and macrostructural properties of manufactured parts, e.g., through internal porosities present in the material by to unmelted powder particles (internal porosity in range of $1.25-2.25 \%$ ). To assess the quality and suitability of additively manufactured implants, a multidimensional verification of the impact of the manufacturing process on the properties of the final product was performed.
\end{abstract}

Keywords Electron Beam Melting (EBM) · Additive manufacturing · Scaffold structures · Finite Element Method (FEM) · Compression test $\cdot$ Computed tomography $(\mathrm{CT}) \cdot$ Ti6Al4V ELI

\section{Introduction}

Scaffold structures have the ability to realize spatially variable material behavior, i.e., stiffness, anisotropy, density, and display attractive properties, such as high stiffness-density ratios [1-4]. They are usually categorized as structures with open or closed cells. The characteristic feature of open-cell cellular structures is the fact that the edges of the main constructive elements (struts, ligaments) meet at vertices, allowing for the passage of fluids. In closed-cell structures, the main constructive elements are walls that meet at the edges

Patrycja Szymczyk

patrycja.e.szymczyk@pwr.edu.pl

1 Centre for Advanced Manufacturing Technologies (CAMT/ FPC), Faculty of Mechanical Engineering, Wroclaw University of Science and Technology, Łukasiewicza 5, 50-371 Wrocław, Poland

2 Department of Mechanics, Materials and Biomedical Engineering, Faculty of Mechanical Engineering, Wroclaw University of Science and Technology, Wrocław, Poland and prevent the passage. Depending on the type of structure and size of the main structural elements, scaffolds are used in such industries as aviation, energy, and medicine.

Open-cell structures are often the first choice as bone replacement material in orthopedic surgery [4]. This type of structure allows for tailoring the mechanical properties of the material to mimic bone and to avoid the major drawback of bulk metals, i.e., stress shielding generated on the surrounding bone tissue.

Implants made from a material with low elastic modulus can reduce the effect of stress shielding. The use of porous metal structures can effectively eliminate this phenomenon as well. The amount of porosity in the implant is considered to be the crucial factor in promoting successful bone integration with a porous structure [5-7]. Open cellular foams and other porous structures are required for bone cell ingrowth to be effective in optimizing biocompatibility $[3,8]$. The ability to control and properly design the shape of the unit cell and surface topography can significantly improve fatigue properties and guarantee long-term use of additively manufactured 
scaffold structures by influencing the reaction occurring at the implant-tissue contact area [9].

Titanium and titanium alloys have been, therefore, widely used as biomedical implant materials since the early $1970 \mathrm{~s}$ and the implants have been available as machined and cast components. The alloys that are preferred for the fabrication of titanium implants are commercially pure titanium (CP-Ti) and titanium alloy Ti6Al4V [10]. It has been demonstrated that mechanical properties of a scaffold depend not only on the volume fraction and size distribution of the pore structures but also on geometrical dimensions of the solid struts [11]. HIP treatment (Hot isostatic pressing) is used to seal internal porosities and defects in material that may affect the strength properties of components produced using Electron Beam Melting (EBM) [12] It is known that ideal scaffolds should be porous, have well-connected networks of pores, whose size should be consistent and suitable for cell migration and infiltration [13]. Complementary analysis of FEM, CT techniques and static compression tests were described by researchers such as Boccacio et al., Alberich-Bayarii et al., Jaecques et al., [14-17]. The Finite Element Method (FEM) analysis allows for obtaining an approximate solution and to develop different models to calculate the load transfer through porous structures. With the use of computed tomography $(\mathrm{CT})$, it is possible to determine the external and internal geometry of the fabricated porous scaffold structures $[18,19]$. Finally, compression tests enable to simulate the behavior of open-cell structures [6]. The effect of porosity of scaffolds made from various materials (porous titanium, bioglass, HA, TPC/alginate) on bone tissue engineering was described by Zhang [20]. The above review paper contains possible mechanisms of how porosity enhances the osteogenic-related functions of cells in vitro and the osteogenic activity of scaffolds in vivo. Moreover, researchers stress the significance of the relationship between the biological and mechanical properties of porous scaffolds [21, 22]. The mechanical properties of porous scaffolds are strongly influenced by their geometry, and therefore should be carefully designed. The necessity for porosity in bone regeneration has been demonstrated by Kuboki et al. [23]. With increasing porosity, the biological properties of scaffolds (such as osteogenic activity) are improved, while their mechanical properties are decreased [20,24].

EBM-fabricated objects are not only characterized by a greater surface roughness than elements produced in a conventional manner, e.g., casting and machining, but also they have a different internal microstructure. The aim of this work was to determine the structural and mechanical characteristics using X-ray CT, compression tests and FEM analysis of additively manufactured Ti6A14V ELI scaffolds intended for the design of modern implants, both in terms of geometric form, and programmed mechanical properties. The selection of the appropriate geometry of the scaffolds is crucial to ensure the desired performance of the implant.

\section{Materials and methods}

Owing to the possibility of modeling various shapes, additive manufacturing is an ideal method for ensuring an optimum shape and structure of the scaffold. It enables the implants to be filled in a way that not only reduces their mass but also brings the implant's mechanical properties as close as possible to the properties of bone tissue. Five types of scaffolds with different geometries were designed and manufactured for the purpose of this study.

\subsection{Numerical simulations}

The scaffold structures were subjected to numerical simulations (using the FEM) in the SIMULIA/ABAQUS 6.13 environment. The scaffold geometry was imported from previously prepared STL files. Such geometry is, in fact, an orphan mesh of a specimen surface which is very problematic to use in a simulation. For this reason, new meshes (based on the initial orphan mesh) were prepared. First, a new quad-based 2D mesh of the surface was made. In the second step a tetrahedral 3D mesh was generated to discretize the entire scaffold model. Finally, the input file was created and exported to the ABAQUS engine. These steps were conducted for all five types of scaffolds described in this paper. Boundary conditions are described in (Fig. 1).

\subsection{Fabrication of scaffolds}

The scaffolds were manufactured using the EBM method (EBM, Arcam, Sweden) with a set of Point-Net parameters, from Ti6Al4V ELI (ASTM F136) alloy powder (Arcam $\mathrm{AB}$, Sweden). The manufacturing process parameters are shown in Table 1. Five types of cubic cellular scaffolds (30 $\mathrm{mm} \times 30 \mathrm{~mm}$ maximum global dimensions) were manufactured in accordance with 3D CAD data model (Table 2).

Process parameters include geometry and construction orientation of the parts, powder chemistry, use of supports and all device settings, included in the "build theme". The standard themes from ARCAM are called "Melt", "Net", "Point-Net" and "Wafer". Based on previous work, we discovered that the "Point-Net" theme ensures process parameters for the fabrication of parts with wireframe geometries [25].

The Ti6Al4V ELI (Arcam AB) powder particles used in the scaffold manufacturing process had a spherical shape. A microscopic examination using scanning electron 


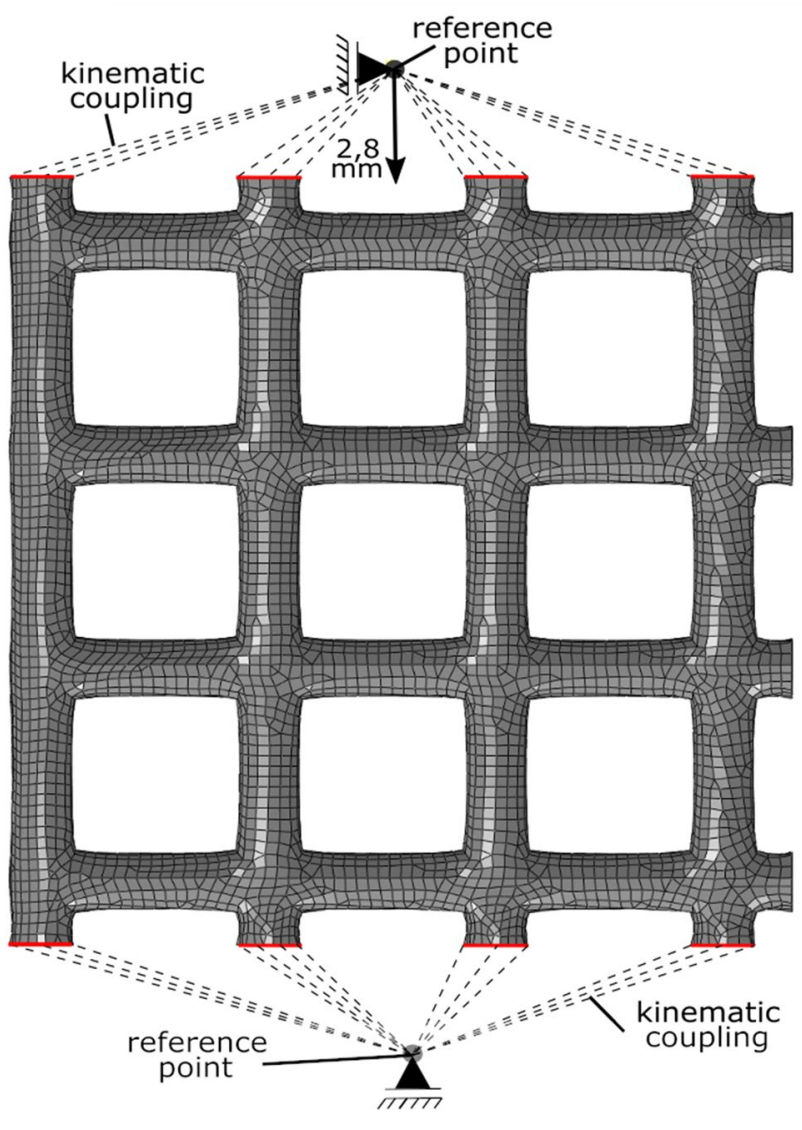

Fig. 1 Boundary conditions

Table 1 EBM manufacturing process parameters

\begin{tabular}{ll}
\hline Parameter & Value \\
\hline Cathode current & $3.4 \mathrm{~mA}$ \\
Time for point & $0.36 \mathrm{~ms}$ \\
Focus offset & $2 \mathrm{~mA}$ \\
Theme & Point-Net
\end{tabular}

microscope ZEISS EVO MA25 showed that the powder particles had diameters ranging from 45 to $100 \mu \mathrm{m}$ (Fig. 2).

The chemical composition (in wt.\%) of powder used is in accordance with the ASTM F136-13 Standard (Table 3).

\subsection{Static compression test}

Five types of scaffolds were designed and then subjected to a static compression test on an Instron 3384 testing machine. The purpose of the test was to determine the characteristics of stress dependence on the strain. Four samples for each type of geometry with external dimensions of $30 \times 30 \times 30 \mathrm{~mm}$ with variable internal geometries (from A-type to E-type) were laid on the pressure plate according to build direction. Probe heads with a pressure of $150 \mathrm{kN}$ with an accuracy class of $0.5 \mathrm{kN}$ were used in the test. The samples were preloaded with a force of $150 \mathrm{~N}$. The traverse speed was $1 \mathrm{~mm} / \mathrm{min}$ and was constant. Before each series of measurements, the head was calibrated. The tests were conducted to the first decrease in the stress value corresponding to the first segment breakdown to determine the maximum stress values that the sample is able to transfer. On the basis of the obtained graphs, substitute Young's modulus for each type was calculated and compared with Young's modulus of bone.

\subsection{Geometric analysis using CT}

Computed tomography was used to obtain the geometry of the samples. The samples were scanned using a CT system (Metrotom 1500, Carl Zeiss, Oberkochen, Germany) and accurate cross sections of every single sample were reconstructed. The system consists of a flat panel detector with a resolution of $1024 \times 1024 \mathrm{px}(400 \mu \mathrm{m}$ pixel size $)$ and 16-bit greyscale, a rotary table and a microfocus $\mathrm{X}$-ray tube with maximum accelerating voltage of $225 \mathrm{kV}$ and maximum current of $1000 \mu \mathrm{A}$. To achieve the maximum resolution for the entire samples, the tube voltage was fixed at $220 \mathrm{kV}$ and the current at $120 \mu \mathrm{A}$. The number of projections carried out during the $360^{\circ}$ rotation of the sample was 800 with 1-s integration time for each one. Each sample was reconstructed with a resolution (voxel size) of $60 \mu \mathrm{m}$. After the reconstruction, the beam hardening correction (BHC) of measurement artifacts was carried out to reduce the disturbances registered for each of the cross sections. The obtained data were analyzed using VG Studio MAX 2.0 software (Volume Graphics GmbH, Heidelberg, Germany). Data segmentation was performed using the local adaptive thresholds method. The geometry analysis was performed with the VG actual-nominal comparison module and the "Enhanced" porosity detection algorithm was used for segmentation of the pores in the specimens. Internal porosity, which determines the amount of voids, was determined using the following Eq. (1):

Porosity[\%] $=\frac{V_{\text {por }}}{V_{m}+V_{\text {por }}} \cdot 100 \%$,

where $V_{\text {por }}$ is the total volume of porosities, and $V_{m}$ is the total volume of material.

\section{Results}

\subsection{Numerical simulations}

During post-processing, the values of reaction force were collected and apparent stresses for all structure types were calculated. In addition, stress fields (according to Huber-Mises hypothesis) for scaffold's models are presented 
Table 2 Scaffolds' CAD data models—detailed information

\begin{tabular}{|c|c|c|c|}
\hline Series name & Single-cell geometry & CAD data model—isometric projection & $\begin{array}{l}\text { Strut thickness } \\
{[\mathrm{mm}]}\end{array}$ \\
\hline A-type & Hexagon & & 3.14 \\
\hline B-type & Grid & & 2.75 \\
\hline C-type & Dodecahedron & & 1.70 \\
\hline D-type & $\mathrm{W}$ & & 1.52 \\
\hline E-type & $X$ & & 1.41 \\
\hline
\end{tabular}


Fig. 2 Images of Ti6Al4V ELI (Arcam $\mathrm{AB}$ ) powder particles, SEM

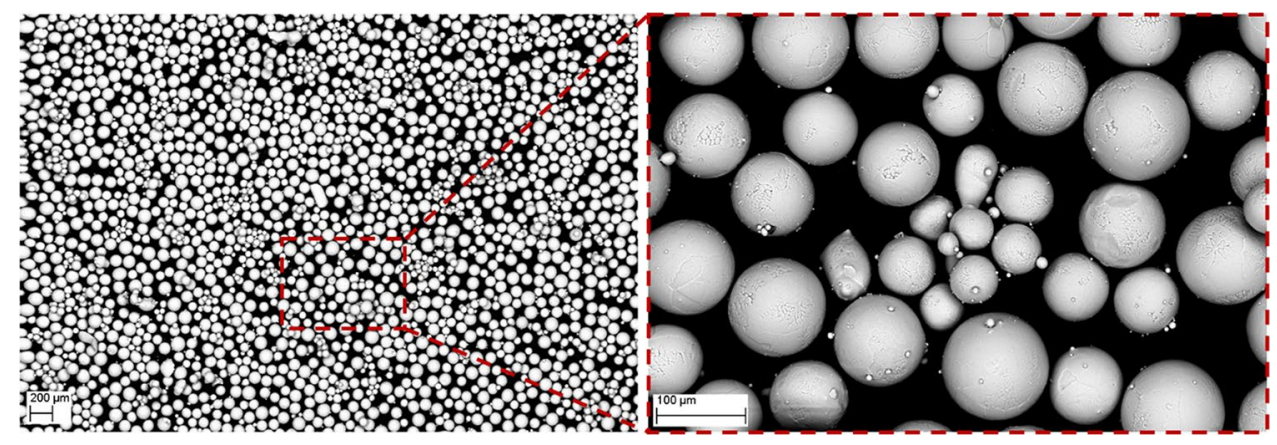

Table 3 Chemical composition of Arcam powder

\begin{tabular}{llllllrr}
\hline & \multicolumn{1}{l}{$\%$} & & & & & \\
\cline { 2 - 8 } & $\mathrm{O}$ & $\mathrm{V}$ & $\mathrm{Al}$ & $\mathrm{Fe}$ & $\mathrm{H}$ & $\mathrm{C}$ & $\mathrm{N}$ \\
\hline Ti6Al4V ELI ASTM F136 & $<0.13$ & $3.5-4.5$ & \multicolumn{1}{l}{$5.5-6.5$} & $<0.25$ & $<0.012$ & $<0.08$ & $<0.05$ \\
Ti6A14V ELI Arcam AB & 0.10 & 4.0 & 6.0 & 0.10 & 0.010 & 0.03 & 0.01 \\
\hline
\end{tabular}

(Fig. 3). For clarity, only the stresses in plane $y z$ are shown (the $z$-axis direction corresponds to the direction of the main displacement).

In Fig. 4, the field of displacement in the $y$-axis direction for B-type scaffold (the simplest geometry) is presented. Extreme displacement suggests a possible mechanism of destruction by shearing, which is in good agreement with the experimental results.

\subsection{Static compression test}

Compressive tests were carried out to evaluate the geometry for compressive strength and stiffness of the scaffolds. The mechanical properties such as compressive strength and substitute Young's modulus on the basis of data from strength-strain curve are shown in Figs. 5 and 6-where letters A-E indicate the type of single-cell geometry and 1-4 are sample numbers.

As a result of the research, it was found that regardless of the analyzed test series, all measurements within the research group were similar and were characterized by a similar shape of the graphs (Fig. 5). The tests of A-type samples were conducted with the maximum compressive stress of $51.34 \mathrm{MPa}$ and strain of 0.08. Sample cracks occurred on supports under the first or second layer. In the case of testing B-type samples, the deformation strain was 0.045 , while the maximum compressive stress (81.04 MPa) was the highest among the all tested series. In samples of this type, cracks occurred at an angle of $45^{\circ}$. In turn, for C-type samples, the maximum compressive stress and deformation level amounted accordingly to $21.96 \mathrm{MPa}$ and 0.75 . Similar results were obtained for the D-type samples- the maximum compressive stress was $20.11 \mathrm{MPa}$, while the deformation was at the level of 0.55. Both C-type and D-type samples cracked at an angle of about $30^{\circ}$. For the test of E-type samples, the maximum compressive stress was at the level of $30.06 \mathrm{MPa}$ with a strain of 0.82 . Samples, as in the case of the B-type, cracked at an angle of $45^{\circ}$.

The calculated substitute Young's modulus for all analyzed scaffold types is in the range of $0.45-2.88 \mathrm{GPa}$ (Fig. 6). The highest value was recorded for B-type samples. Also, the highest value of compressive strengths was found for this type (approx. $79 \mathrm{MPa}$ ). However, the greatest deformations occurred in A-type scaffolds and amounted to approx. $0.9 \mathrm{~mm}$. It is noteworthy that C-type scaffolds cracked, while all others crumbled and disintegrated into parts. All measurement results for the samples included in a given type are similar and the deviations do not exceed $15 \%$ as shown in Fig. 6.

Referring to the results obtained using the FEM method and static compression test, it was observed that the course of the curves has a similar character for each type of scaffold geometry (Fig. 7). The slight differences between these curves are mainly due to simplifications of the material model implemented in FEM which did not include internal porosities occurring in struts of scaffolds. The issue of implementing imperfect material model in FEM analysis requires further consideration.

\subsection{Geometric analysis using CT}

Computed tomography allowed for evaluation of inner and outer geometry of the manufactured scaffolds. Volumetric models of scaffolds were obtained and then, during the first stage of the CT analysis, the designed geometry of scaffolds 


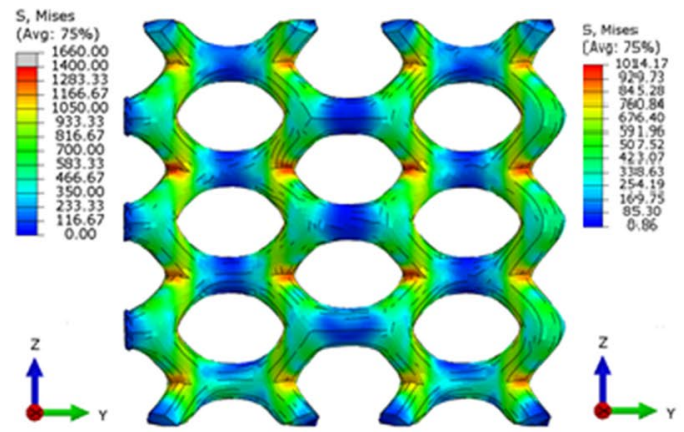

(a)

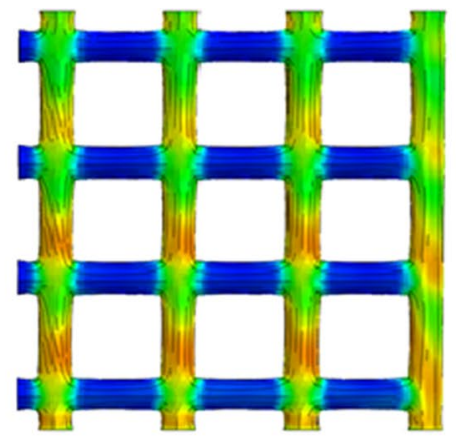

(b)

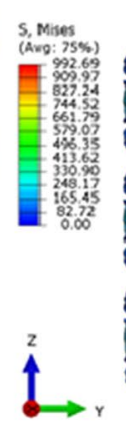

(c)

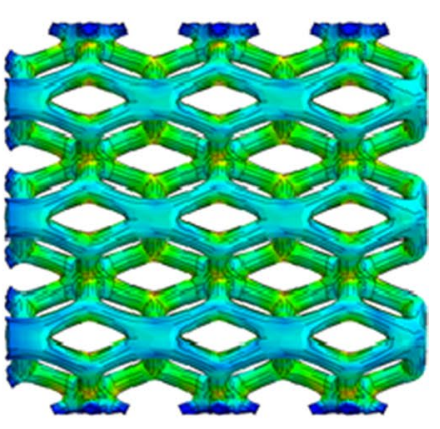

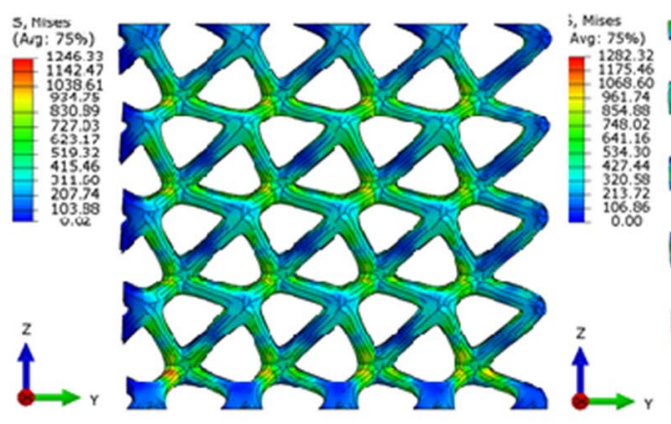

(d)

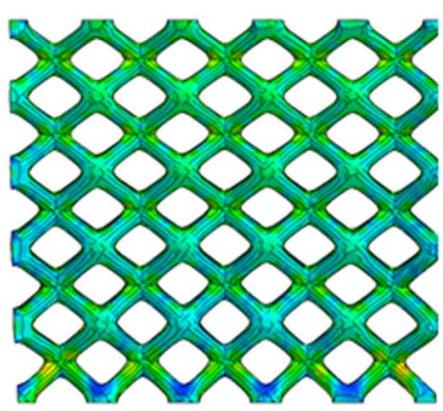

(e)

Fig. 3 Distribution of stresses (according to Huber-Mises hypothesis): a A-type specimen, b B-type specimen, c C-type specimen, d D-type specimen and e E-type specimen
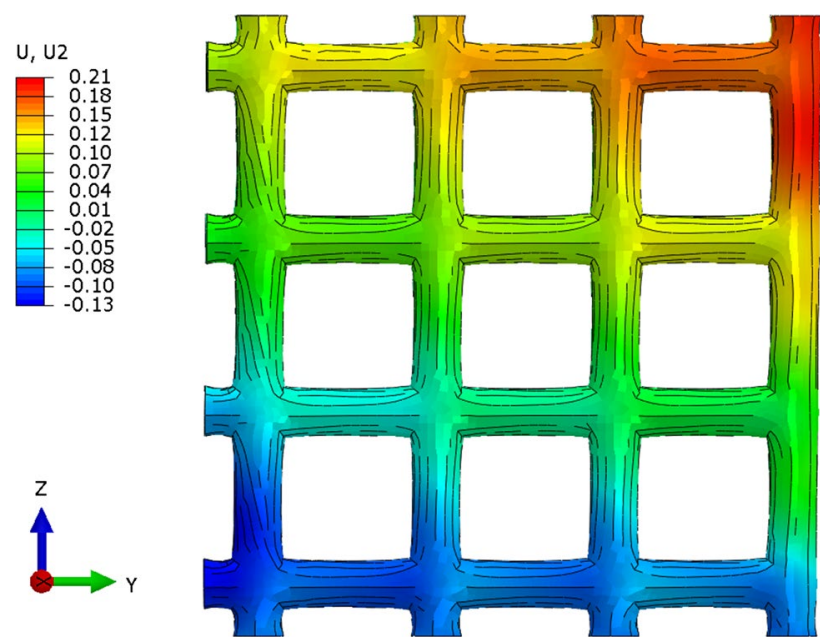

Fig. 4 Field of displacement in the $y$-axis direction of an exemplary scaffold (B-type)

was compared with the actual geometry of the fabricated structures.

The actual models (volumetric models from CT) were fitted to the nominal models (from CAD) using the "least squares" method. The results of geometry comparison are presented as color maps (Fig. 8).

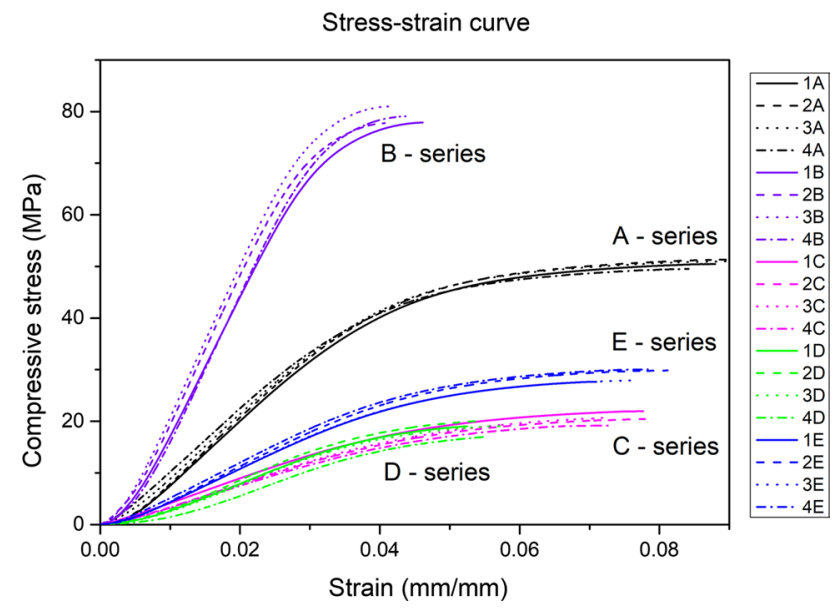

Fig. 5 Stress-strain curve of the tested series of scaffolds

Owing to the small size of geometric porosities and the scaffold density, D-type and E-type geometries were most accurately reproduced during the manufacturing process, (Fig. 9a). The geometry deviation values indicate that 90\% of the surface of A-type and B-type samples were in the range of up to $\pm 300 \mu \mathrm{m}$, for C-type sample up to $\pm 280 \mu \mathrm{m}$, and for D-type and E-type samples up to $\pm 260 \mu \mathrm{m}$ (Fig. 9b). 


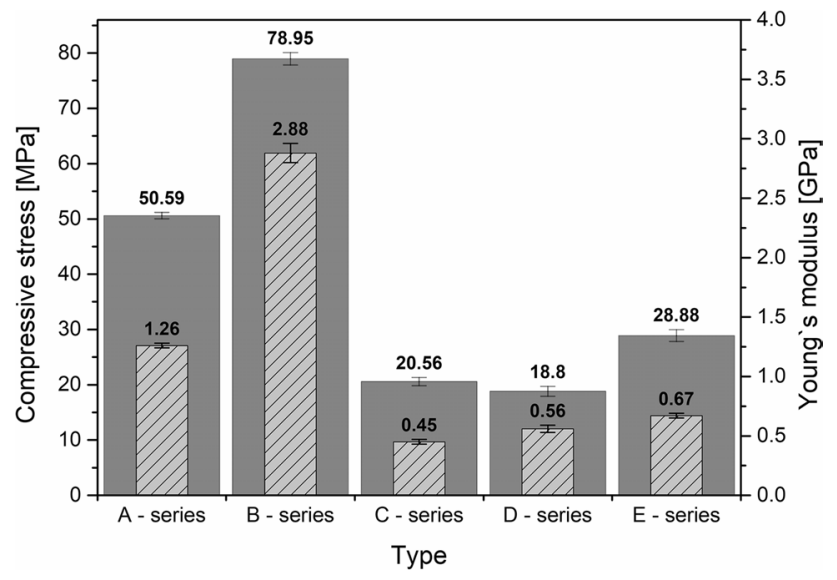

Fig. 6 Compressive stress and substitute Young's modulus of different types of scaffolds

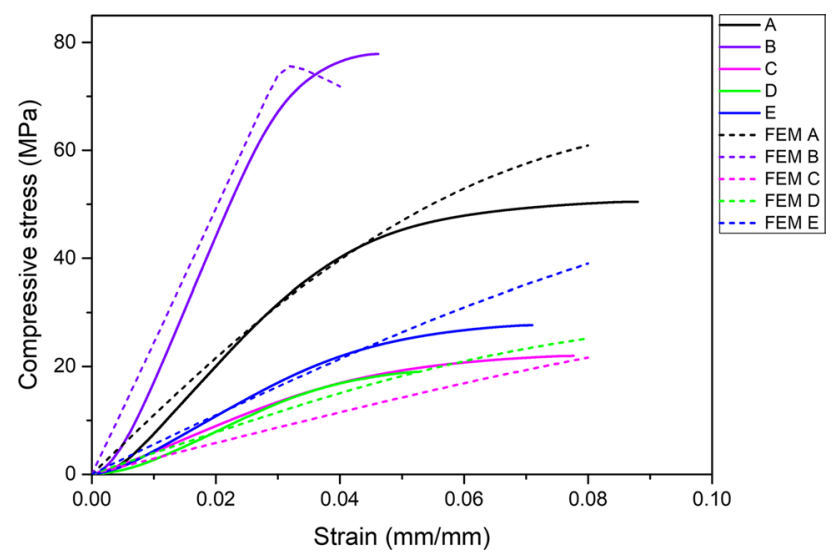

Fig. 7 Relationship between static compression test and FEM analysis

The highest deviations from the values given by the CAD model were noted at the supports and at places furthest away from the supports. In the case of A-type and B-type geometry, the largest material underflow was recorded in the vicinity of the supports. The differences in the registered deviations can be explained by phenomenon of heat propagation from melt pool causing partial melting or sintering of surrounding powder particles to the surface [26].

In the next stage, the total porosity and volume of individual pores of the manufactured scaffolds were determined. The 2D CT cross sections show internal unmelted particles in the examined material which tend to aggregate into porosities (Fig. 10).

There is a noticeable relationship between the size of the porosity and the thickness of the struts from which the material was made. Due to the high aggregation of the nonmelted material, a higher tendency to create larger porosities is visible in samples with thicker struts-A-, B- and C-type structures have the largest amount of porosity with the largest diameter; while D- and E-type ones have the least porosity with the smallest pore diameters (Fig. 10).

The applied CT measurement parameters enabled the reconstruction of entire samples (Fig. 11) and registration of pores with diameters exceeding $147 \mu \mathrm{m}$. Pores with the largest equivalent diameters [27] (larger than $7 \mathrm{~mm}$ ) and the most extensive surface areas (greater than $40 \mathrm{~mm}^{2}$ ) were registered for C-type sample. Pores with the smallest equivalent diameters (less than $3.5 \mathrm{~mm}$ ) and the smallest surfaces (less than $20 \mathrm{~mm}^{2}$ ) were recorded for D- and E-type samples (Fig. 12a).

The porosity analysis showed that the highest internal porosity exceeding $2.25 \%$ was recorded for C-type geometry, while the lowest for D-type and E-type geometries (slightly over $1.25 \%$ ) (Fig. 12a). To better characterize the nature of the pores, a region of interest (ROI) of the B-type sample was reconstructed with a resolution of $20 \mu \mathrm{m}$, which allowed for demonstrating that the registered pores are partially filled with unmelted powder (Fig. 13).

The high-resolution porosity analysis allowed for showing a larger number of pores registered in the selected fragment and indicates a larger surface area of recorded discontinuities.

\section{Discussion}

To reduce the weight and effective stiffness of titanium implants, the implant structure has to be made porous [4]. Previous studies have investigated design parameters of scaffold structures to optimize their biomechanical properties such as osteoinductivity, osteoconductivity, biodegradability, and mechanical integrity to ensure their optimum properties as implant structure promoting bone repair. Scaffold design parameters should be tailored to address distinct healing behaviors [5]. The porous metallic scaffolds have less elastic modulus, close to that of human bone, thereby facilitating bone ingrowth and biological fixation. Porosity also guarantees better tissue nutrition around the scaffold $[10,13]$.

The substitute Young's modulus designated within the research is in the range of 0.5-3 GPa (Fig. 6). The highest value was recorded for B-type samples, while the smallest for C-type samples. The results for samples within each type are similar, with deviations falling within the range of up to $10 \%$. The huge spread of results between the test series shows that the geometry of the scaffold has a significant impact on its strength properties. This is especially true for cancellous bone, where the Young's modulus can vary from 0.1 to $4.5 \mathrm{GPa}$ depending on bone density and trabecular orientation [28]. A comparison of the obtained results to the 
Fig. 8 Color-coded geometry deviations of actual models from nominal models: a A-type specimen, b B-type specimen, c C-type specimen, d D-type specimen and e E-type specimen

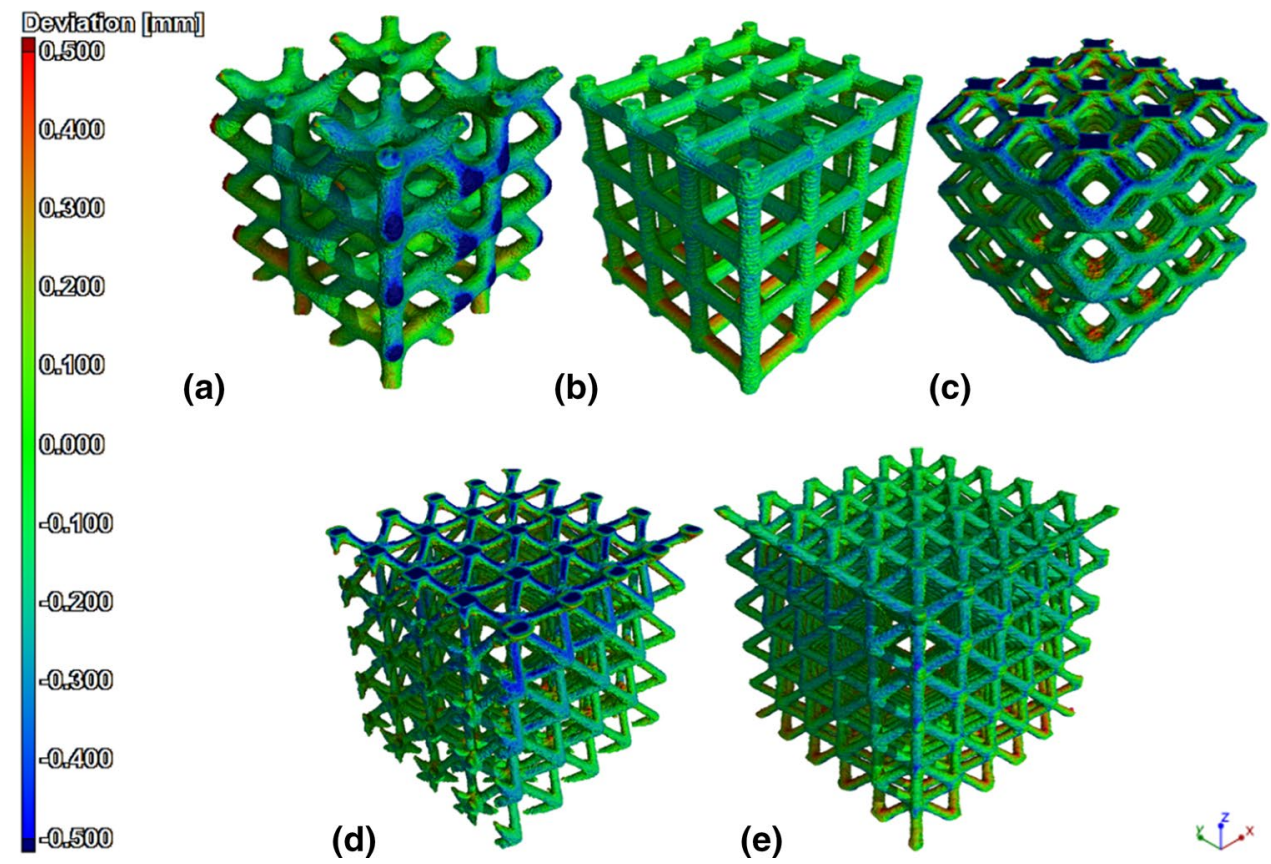

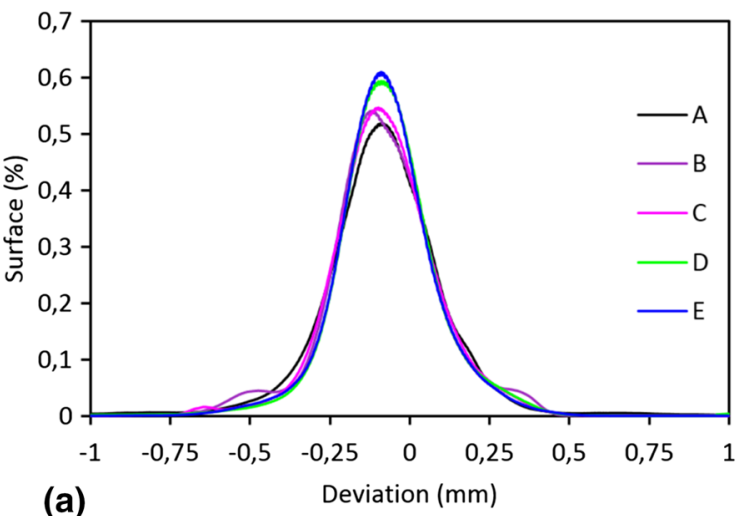

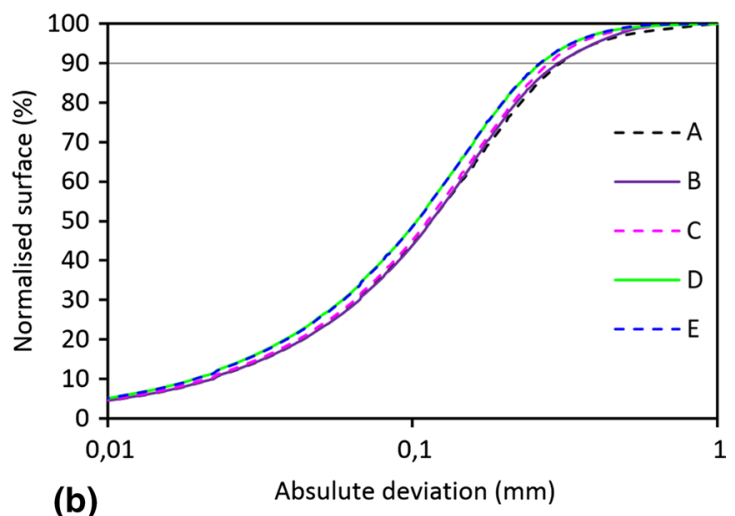

Fig. 9 Dimensional accuracy of scaffolds: a deviation histogram, b cumulated histogram-90\% of the surface is within the limits of 0.306 mm for A-type sample, $0.301 \mathrm{~mm}$ for B-type sample, $0.280 \mathrm{~mm}$ for C-type sample, $0.264 \mathrm{~mm}$ for D-type sample and $0.262 \mathrm{~mm}$ for E-type sample

Fig. 10 2D CT cross section: a A-type specimen, b B-type specimen, $\mathbf{c}$ C-type specimen, d D-type specimen, e E-type specimen

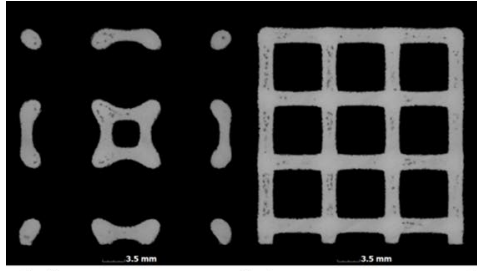

(a) (b)

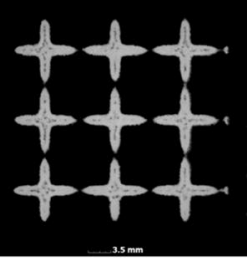

(c)

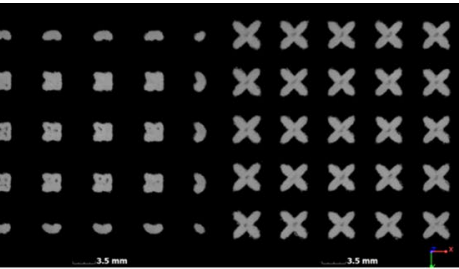

(d) (e)
Young's modulus of the cancellous bone (1.37 GPa) [27] has shown that the closest value was obtained for A-type samples (1.26 GPa). It is possible that the use of A-type geometry structures as a fill of the modeled implant could reduce the phenomenon of stress shielding. 


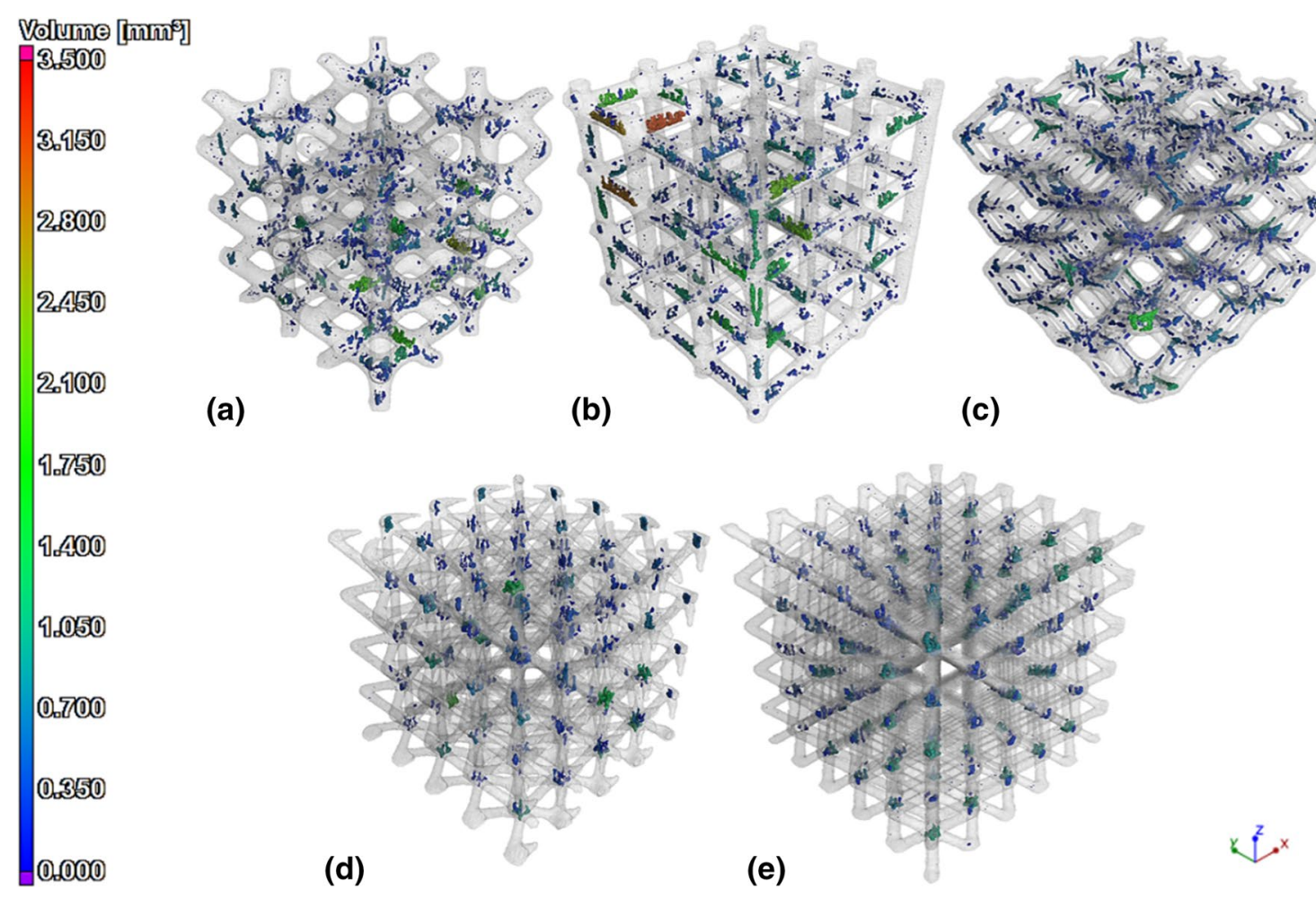

Fig. 11 3D transparency view of specimens: a A-type specimen, b B-type specimen, c C-type specimen, $\mathbf{d}$ D-type specimen and e E-type specimen
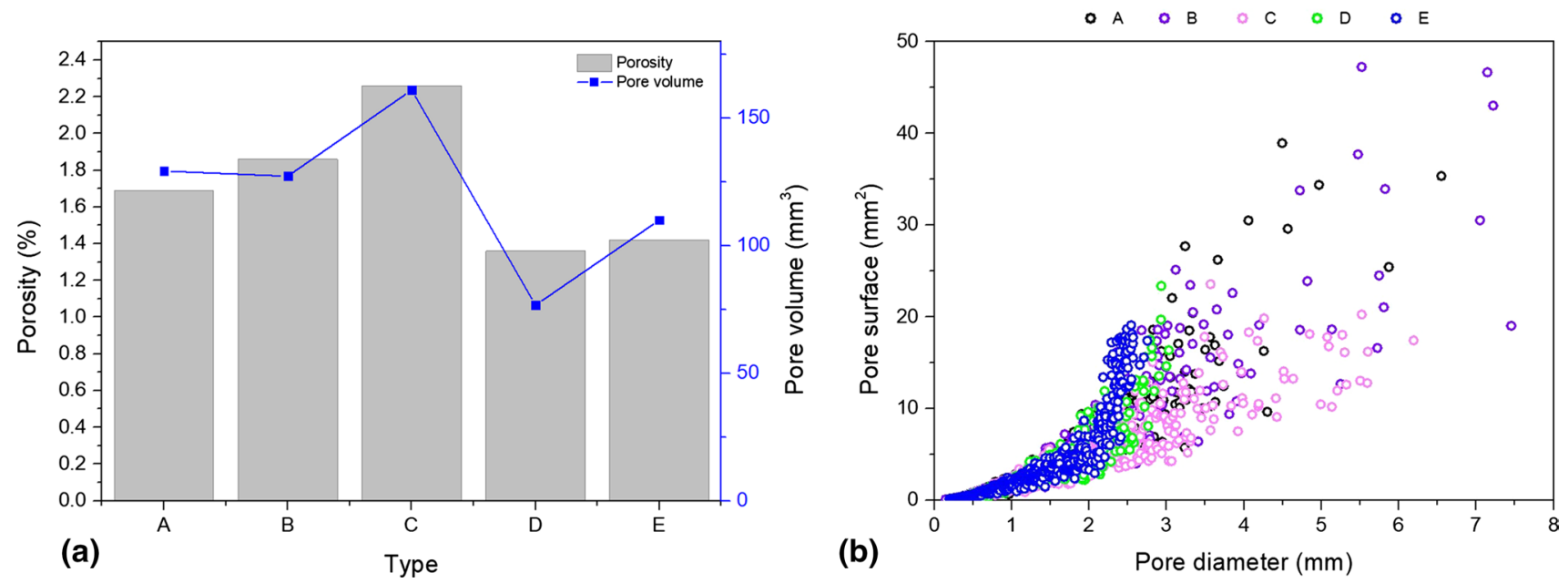

Fig. 12 Porosity analysis of scaffolds: a total material porosity and pore volume of examined scaffolds and $\mathbf{b}$ pore surface and pore equivalent diameter

The CT tests have shown that the internal scaffold microstructure contains porosities (Fig. 11) in the form of non-melted powder particles (Fig. 13b). It causes that during compression, a phenomenon resulting in the reduction of stresses on the inner surfaces of the revealed defects occurs. The porosities developed in the microscale should be treated as geometrical features in the mesoscale [29].
In addition, the objects manufactured by EBM are characterized by a greater surface roughness than elements manufactured in a conventional way which clearly affects the strength properties of the finished parts (Fig. 8). Roughness and surface topography are a consequence of the presence of partially sintered powder particles to the surface $[8,14]$. However, the aforementioned feature of 


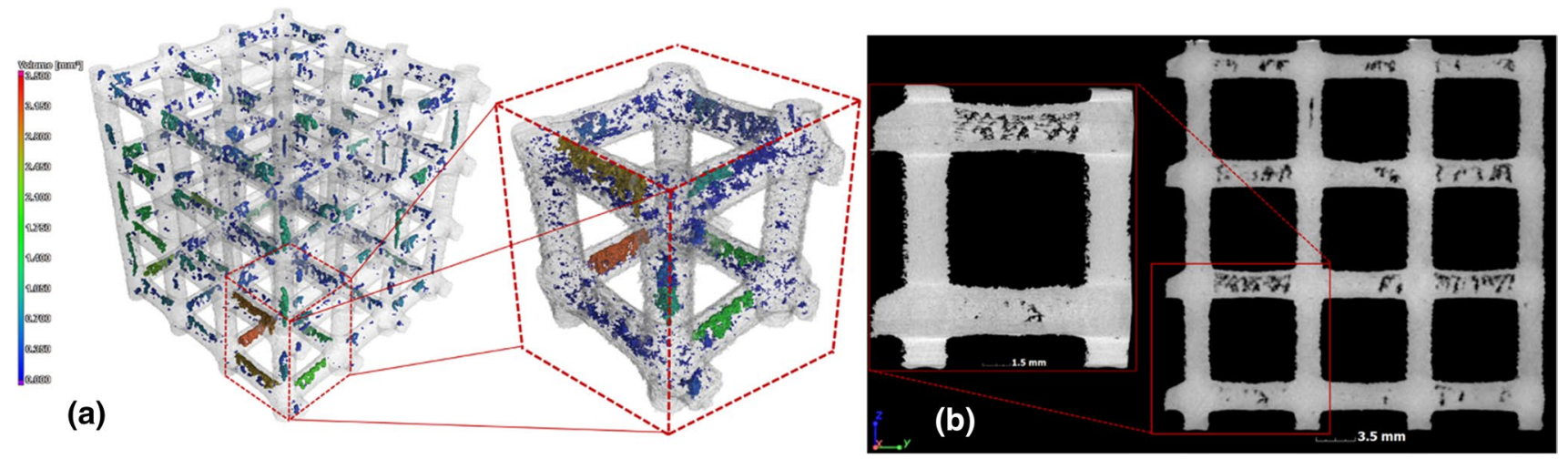

Fig. 13 Porosity analysis of the scaffolds: a 3D view of a ROI reconstructed with a resolution of $20 \mu \mathrm{m}$, and $\mathbf{b} 2 \mathrm{D}$ view with visible partial filling of the pores with unmelted powder

the technology also depends on the use of correct process parameters, such as beam current, offset focus and scan speed along with the use of high-quality powder material and sample thickness $[26,30]$. The above is particularly noticeable when comparing the characteristics of the compression simulation to the actual results from the static compression test. To reflect the real conditions prevailing in the material, the internal porosity, as well as surface topography should be implemented in the FEM model.

Excessive surface roughness adversely affects the interaction between the implant and the surrounding bone and may cause an increased release of metal ions to the surrounding tissues. It can also contribute to the formation of stresses that are unfavorable from the point of view of mechanical properties and may cause impede cell adhesion. On the other hand, a smooth surface, as compared with a moderately rough one, does not stimulate the osseointegration process so intensively because it does not provide adequate retention due to insufficient friction coefficient. In addition, on smooth surfaces, cells tend to flatten, which hinders their nutrition and growth [31-34]. Therefore, each change in the roughness parameter can have profound consequences on the bone regeneration process. Porous metals should have sufficient strength to be able to resist stresses and physiological loadings that are imposed on them, while maintaining their original size and shape. The scaffold should provide sufficient mechanical strength to support itself until the new bone tissue is completely formed into the pores [35]. Many experimental studies have attempted to determine the optimal scaffolding properties for use in tissue engineering, and in particular reconstruction of bone tissue, but no algorithm was provided that would allow, for example, the modeling of strength parameters and porosity of the scaffold material. Research has shown that bone regeneration during healing can be simulated using mechanoregulation algorithms [36, 37]. The global porosity of the scaffold structures should match the porosities of various types of bones to achieve the best fitment with real conditions. Bone is often classified as "cortical" (less than $20 \%$ porosity) or "trabecular" (typically 50-90\% contribution of porosity). The presence of Haversian canal systems can be used as defining characteristic of cortical bone [38].

Due to the fact that the designed geometry of the studied scaffolds corresponds to the typical porosity of trabecular bone (from 81 to $84.5 \%$ including internal porosities of the material), the mechanical properties were compared with the results of other scientists and these values were compared with the parameters corresponding to bone tissue.

The research results available in the literature (Table 4) concerning the design and manufacture of 3D structures mimicking cancellous bone tissue clearly show that foam structures described by Cheng et al. [39] present the best strength parameters in relation to porosity. Unfortunately, the above solutions have a considerable drawback, i.e., their internal geometry cannot be controlled, with such control being possible with the use of modern manufacturing techniques such as AM. The research results obtained as part of this study indicate that through adequate control of porosity and strut thickness, it is possible to match the properties and architecture of bone tissue, which is confirmed by the results obtained for structures C-type, D-type and E-type (Fig. 14).

Additive manufacturing technologies, especially from the powder bed fusion category, allow for the design and fabrication of cellular and porous structures. The design of cellular or lattice metal structures is still far from a defined set of theoretical methods, such as in the case of solid mechanics. However, the multiscale approach presented could set the line of thought to develop design methodologies $[29,43]$. 


\section{Conclusion}

The design and production of 3D structures in the form of scaffolds should be treated as a multidimensional problem for optimization. Suitable identification of properties that can affect the behavior of loaded scaffolds should be analyzed in micro- and mesoscale. The micro-scale aspects include features obtained as a result of manufacturing technology and are related to the material's microstructure. The mesoscale level takes into account the size of the elementary cell of the scaffold, its shape, orientation and topology. All these features affect the final behavior of the structure under load.

During scaffold design, particular attention should be paid to the influence of porosity that may occur in the material after manufacturing process. To reflect the actual loading of material using FEM analysis, the material model should be properly defined, taking into account the possibility of occurrence of local porosities in the form of non-melted particles, which may behave like micro-bearings, causing a different load transfer. Moreover, geometrical deviations that occur in the manufactured scaffolds are related to nature of the process and used process parameters. They have an influence on compressive behavior resulting from local surpluses and insufficiencies of material. By changing elementary cell dimensions in scaffold structures, strut thickness and orientation, the structures can be fitted in relation to the design equivalent strength and optimized to clinical requirements. The design of scaffolds for tissue engineering is a multiscale and multidisciplinary area where considerable further research is needed.
Table 4 Geometrical and mechanical properties of different 3D structures processed with EBM

\begin{tabular}{llllll}
\hline Type & $\begin{array}{l}\text { Strut } \\
\text { diameter } \\
{[\mathrm{mm}]}\end{array}$ & $\begin{array}{l}\text { Total } \\
\text { porosity } \\
{[\%]}\end{array}$ & $\begin{array}{l}\text { Compressive } \\
\text { strength [MPa] }\end{array}$ & $\begin{array}{l}\text { Young's } \\
\text { modulus } \\
{[\mathrm{GPa}]}\end{array}$ & References \\
\hline Trabecular bone & - & 90 & $5-8$ & 0.44 & {$[40]$} \\
Ti6A14V EBM foam & 1.04 & 91.65 & 3.8 & 0.19 & {$[39]$} \\
Ti6A14V EBM foam & 0.84 & 90.08 & 4.5 & 0.49 & \\
Ti6A14V EBM mesh & 1.08 & 86.00 & 12.4 & 0.54 & \\
Ti6A14V EBM mesh & 0.77 & 73.36 & 59.4 & 2.99 & \\
Ti6A14V EBM homogenously porous & 0.5 & 65 & 110 & 2.7 & {$[41]$} \\
Ti6A14V EBM gradient porous & 0.5 & 45.6 & 366.5 & 64.8 & \\
Ti6A14V EBM rectangular strut & 0.941 & 50.75 & 163.02 & 2.92 & {$[11]$} \\
Ti6A14V EBM rectangular strut & 0.905 & 60.41 & 117.05 & 2.68 & \\
Ti6A14V EBM rectangular strut & 0.882 & 70.32 & 83.13 & 2.13 & \\
Ti6A14V EBM gyroid & 0.49 & 82 & 24.4 & 0.635 & {$[42]$} \\
Ti6A14V EBM gyroid & 0.60 & 85 & 21.3 & 0.824 & \\
\hline
\end{tabular}
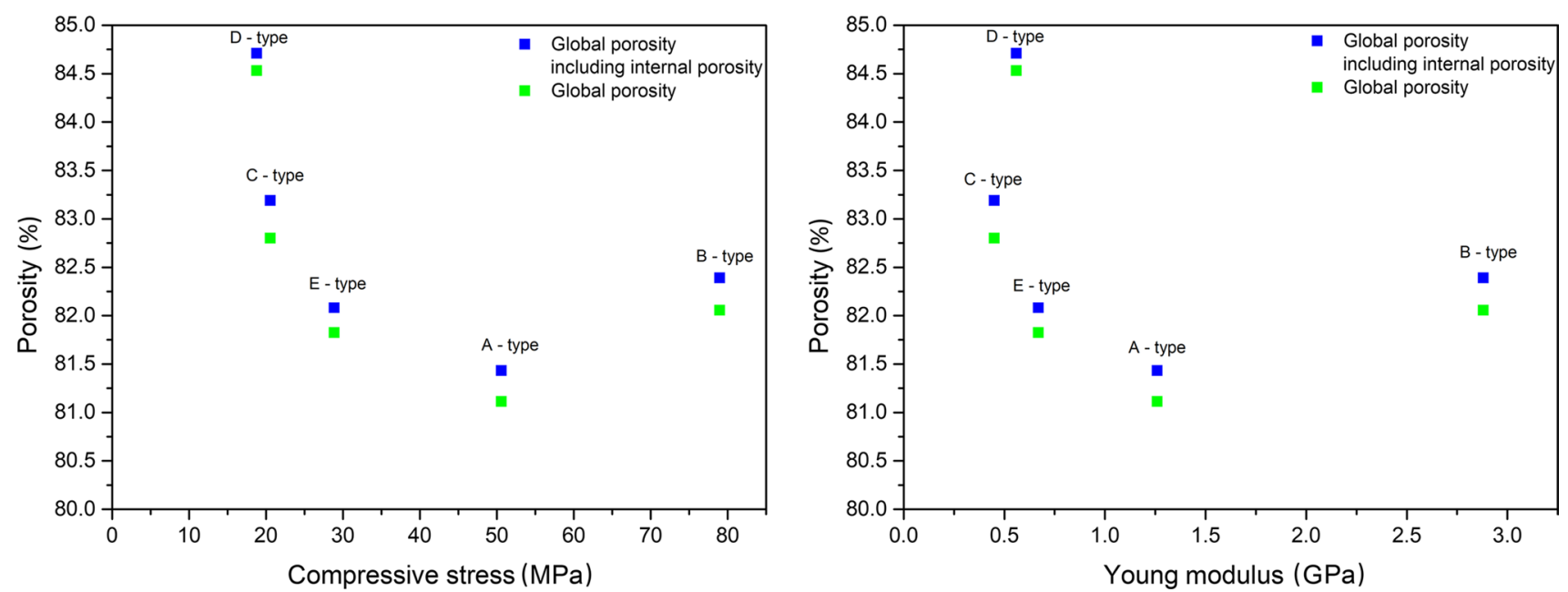

Fig. 14 Relationship between porosity and compressive stress or Young's modulus 
Open Access This article is licensed under a Creative Commons Attribution 4.0 International License, which permits use, sharing, adaptation, distribution and reproduction in any medium or format, as long as you give appropriate credit to the original author(s) and the source, provide a link to the Creative Commons licence, and indicate if changes were made. The images or other third party material in this article are included in the article's Creative Commons licence, unless indicated otherwise in a credit line to the material. If material is not included in the article's Creative Commons licence and your intended use is not permitted by statutory regulation or exceeds the permitted use, you will need to obtain permission directly from the copyright holder. To view a copy of this licence, visit http://creativecommons.org/licenses/by/4.0/.

\section{References}

1. Wallach JC, Gibson LJ. Mechanical behavior of a three-dimensional truss material. Int J Solids Struct. 2001;38:7181-96. https ://doi.org/10.1016/S0020-7683(00)00400-5

2. Gümrük R, Mines RAW. Compressive behaviour of stainless steel micro-lattice structures. Int J Mech Sci. 2013;68:125-39. https://doi.org/10.1016/j.ijmecsci.2013.01.006.

3. Vigliotti A, Pasini D. Stiffness and strength of tridimensional periodic lattices. Comput Methods Appl Mech Eng. 2012;229232:27-43. https://doi.org/10.1016/j.cma.2012.03.018.

4. Meyers MA, Chen PY, Lin AYM, Seki Y. Biological materials: Structure and mechanical properties. Prog Mater Sci. 2008;53:1-206. https://doi.org/10.1016/j.pmatsci.2007.05.002.

5. Basalah A, Shanjani Y, Esmaeili S, Toyserkani E. Characterizations of additive manufactured porous titanium implants. J Biomed Mater Res Part B Appl Biomater. 2012;100B:1970-9. https://doi.org/10.1002/jbm.b.32764.

6. Szymczyk P, Ziółkowski G, Junka A, Chlebus E. Application of Ti6Al7 Nb alloy for the manufacture of biomechanical functional structures (BFS) for custom-made bone implants. Materials (Basel). 2018;11:1-16. https://doi.org/10.3390/ma11060971

7. Pawlak A, Szymczyk P, Ziolkowski G, Chlebus E, Dybala B. Fabrication of microscaffolds from Ti-6Al-7Nb alloy by SLM. Rapid Prototyp J. 2015;21:393-401. https://doi.org/10.1108/ RPJ-10-2013-0101.

8. Murr LE, Amato KN, Li SJ, Tian YX, Cheng XY, Gaytan SM, Martinez E, Shindo PW, Medina F, Wicker RB. Microstructure and mechanical properties of open-cellular biomaterials prototypes for total knee replacement implants fabricated by electron beam melting. J Mech Behav Biomed Mater. 2011;4:1396-411. https://doi.org/10.1016/j.jmbbm.2011.05.010.

9. Ren D, Li S, Wang H, Hou W, Hao Y, Jin W, Yang R, Misra RDK, Murr LE. Fatigue behavior of Ti-6Al-4V cellular structures fabricated by additive manufacturing technique. J Mater Sci Technol. 2019;35:285-94. https://doi.org/10.1016/j.jmst.2018.09.066.

10. Sidambe AT. Biocompatibility of advanced manufactured titanium implants-a review. Materials (Basel). 2014;7:8168-88. https:// doi.org/10.3390/ma7128168.

11. Parthasarathy J, Starly B, Raman S, Christensen A. Mechanical evaluation of porous titanium (Ti6Al4V) structures with electron beam melting (EBM). J Mech Behav Biomed Mater. 2010;3:249_ 59. https://doi.org/10.1016/j.jmbbm.2009.10.006.

12. Benzing J, Hrabe N, Quinn T, White R, Rentz R, Ahlfors M. Hot isostatic pressing (HIP) to achieve isotropic microstructure and retain as-built strength in an additive manufacturing titanium alloy (Ti-6Al-4V). Mater Lett. 2019;257:126690. https://doi. org/10.1016/j.matlet.2019.126690.
13. An J, Teoh JEM, Suntornnond R, Chua CK. Design and 3D printing of scaffolds and tissues. Engineering. 2015;1:261-8. https:// doi.org/10.15302/J-ENG-2015061.

14. Boccaccio A, Messina A, Pappalettere C, Scaraggi M. Finite element modelling of bone tissue scaffolds. Cambridge: Woodhead Publishing Limited; 2014. https://doi.org/10.1533/9780857096 739.4.485.

15. Boccaccio A, Uva AE, Fiorentino M, Mori G, Monno G. Geometry design optimization of functionally graded scaffolds for bone tissue engineering: a mechanobiological approach. PLoS ONE One. 2016. https://doi.org/10.1371/journal.pone.0146935.

16. Alberich-Bayarri A, Moratal D, Ivirico JLE, Hernandez JCR, Valles-Lluch A, Marti-Bonmati L, Estelles J, Mano JF, Pradas MM, Ribelles JL, Salmeron-Sanchez M. Microcomputed tomography and microfinite element modeling for evaluating polymer scaffolds architecture and their mechanical properties. J Biomed Mater Res - Part B Appl Biomater. 2009;91:191-202. https://doi. org/10.1002/jbm.b.31389.

17. Jaecques SVN, Van Oosterwyck H, Muraru L, Van Cleynenbreugel T, De Smet E, Wevers M, Naert I, Vander Sloten J. Individualised, micro CT-based finite element modelling as a tool for biomechanical analysis related to tissue engineering of bone. Biomaterials. 2004;25:1683-96. https://doi.org/10.1016/S0142 -9612(03)00516-7.

18. Ziolkowski G, Szymczyk P, Dybala B, Chlebus E, Pawlak A. Geometric characteristics of scaffolds made by additive manufacturing. Powder Metall Met Ceram. 2015;54:136-9. https://doi. org/10.1007/s11106-015-9690-y.

19. Ziółkowski G, Chlebus E, Szymczyk P, Kurzac J. Application of X-ray CT method for discontinuity and porosity detection in 316L stainless steel parts produced with SLM technology. Arch Civ Mech Eng. 2014;14:608-14. https://doi.org/10.1016/j. acme.2014.02.003.

20. Zhang K, Fan Y, Dunne N, Li X. Effect of microporosity on scaffolds for bone tissue engineering, Regen. Biomater. 2018. https:// doi.org/10.1093/rb/rby001.

21. Velasco MA, Lancheros Y, Garzón-Alvarado DA. Geometric and mechanical properties evaluation of scaffolds for bone tissue applications designing by a reaction-diffusion models and manufactured with a material jetting system. J Comput Des Eng. 2016;3:385-97. https://doi.org/10.1016/j.jcde.2016.06.006.

22. Montazerian H, Davoodi E, Asadi-Eydivand M, Kadkhodapour J, Solati-Hashjin M. Porous scaffold internal architecture design based on minimal surfaces: a compromise between permeability and elastic properties. Mater Des. 2017;126:98-114. https://doi. org/10.1016/j.matdes.2017.04.009.

23. Kuboki $Y$, Takita $H$, Kobayashi D, Tsuruga E, Inoue M, Murata M, Nagai N, Dohi Y, Ohgushi H. BMP-Induced osteogenesis on the surface of hydroxyapatite with geometrically feasible and nonfeasible structures: topology of osteogenesis. J Biomed Mater Res. 1998;39:190-9. https://doi.org/10.1002/(SICI)1097-4636(19980 2)39:2\%3c190:AID-JBM4\%3e3.0.CO;2-K.

24. Franco J, Hunger P, Launey ME, Tomsia AP, Saiz E. Direct write assembly of calcium phosphate scaffolds using a waterbased hydrogel. Acta Biomater. 2010;6:218-28. https://doi. org/10.1016/J.ACTBIO.2009.06.031.

25. Hoppe V, Szymczyk P, Madeja M. Influence of scanning strategy on geometrical accuracy and mechanical properties of electron beam-melted Ti6Al4V scaffolds. In: Wysoczański T (ed) Nauk. Badania i Doniesienia Nauk. 2018-Nauk. Tech. i Ścisłe, 2018; pp 40-50. http://www.konferencja-eureka.pl/assets/docs/nauki -techniczne-i-scisle-2.pdf. Accessed 20 Jan 2019.

26. Safdar A, He HZ, Wei LY, Snis A, Chavez De Paz LE. Effect of process parameters settings and thickness on surface roughness of EBM produced Ti-6Al-4V. Rapid Prototyp J. 2012;18:401-8. https://doi.org/10.1108/13552541211250391. 
27. Sugiura T, Yamamoto K, Horita S, Murakami K, Kirita T. Micromotion analysis of different implant configuration, bone density, and crestal cortical bone thickness in immediately loaded mandibular full-arch implant restorations: a nonlinear finite element study. Clin Implant Dent Relat Res. 2018;20:43-9. https://doi. org/10.1111/cid.12573.

28. Turner $\mathrm{CH}$, Burr DB. Basic biomechanical measurements of bone: a tutorial. Bone. 1993;14:595-608. https://doi.org/10.1016/87563282(93)90081-K.

29. E. Arrieta, Comprehensive finite element modeling of Ti-6Al-4V cellular solids fabricated by electron beam melting. 2017; https ://search.proquest.com/openview/51759f648d55a2317dd4acbb1 eb3f2f3. Accessed 18 Dec 2018.

30. Vo TH, Museau M, Vignat F, Villeneuve F, Ledoux Y, Ballu A. Typology of geometrical defects in Electron Beam Melting. Procedia CIRP. 2018;75:92-7. https://doi.org/10.1016/j.proci r.2018.04.033.

31. Le Guehennec L, Lopez-Heredia MA, Enkel B, Weiss P, Amouriq Y, Layrolle P. Osteoblastic cell behaviour on different titanium implant surfaces. Acta Biomater. 2008;4:535-43. https://doi. org/10.1016/j.actbio.2007.12.002.

32. Kasemo B, Lausmaa J. Aspects of surface physics on titanium implants. Swed Dent J Suppl. (1985); 28:19-36. https://www.ncbi. nlm.nih.gov/pubmed/3904061. Accessed 15 Nov 2018.

33. Anselme K, Bigerelle M. Statistical demonstration of the relative effect of surface chemistry and roughness on human osteoblast short-term adhesion. J Mater Sci Mater Med. 2006;17:471-9. https://doi.org/10.1007/s10856-006-8475-8.

34. Zareidoost A, Yousefpour M, Ghaseme B, Amanzadeh A. The relationship of surface roughness and cell response of chemical surface modification of titanium. J Mater Sci Mater Med. 2012;23:1479-88. https://doi.org/10.1007/s10856-012-4611-9.

35. Nouri A, Hodgson PD, Wen CE. Biomimetic porous titanium scaffolds for orthopedic and dental applications. Biomimetics Learn Nat. 2010. https://doi.org/10.5772/8787.

36. Byrne DP, Lacroix D, Planell JA, Kelly DJ, Prendergast PJ. Simulation of tissue differentiation in a scaffold as a function of porosity, Young's modulus and dissolution rate: application of mechanobiological models in tissue engineering. Biomaterials. 2007;28:5544-54. https://doi.org/10.1016/J.BIOMATERIA LS.2007.09.003.

37. Sandino C, Checa S, Prendergast PJ, Lacroix D. Simulation of angiogenesis and cell differentiation in a CaP scaffold subjected to compressive strains using a lattice modeling approach. Biomaterials. 2010;31:2446-522. https://doi.org/10.1016/j.biomateria 1s.2009.11.063.

38. Roy ME, Rho JY, Tsui TY, Evans ND, Pharr GM. Mechanical and morphological variation of the human lumbar vertebral cortical and trabecular bone. J Biomed Mater Res. 1999;44:191-7. https://doi.org/10.1002/(SICI)1097-4636(199902)44:2\%3c191 :AID-JBM9\%3e3.0.CO;2-G.

39. Cheng XY, Li SJ, Murr LE, Zhang ZB, Hao YL, Yang R, Medina $\mathrm{F}$, Wicker RB. Compression deformation behavior of Ti-6Al-4V alloy with cellular structures fabricated by electron beam melting. J Mech Behav Biomed Mater. 2012; 153-162. https://ac.els-cdn. com/S1751616112002639/1-s2.0-S1751616112002639-main. pdf?_tid=01a5f002-878e-4ab8-a3f7-88a148b912f0\&acdna $\mathrm{t}=1544696874 \_b d 4 c 0 d 54 e c 56 b 6 a 72 a 03 a 1829 b a d 1 a 6 d$. Accessed 13 Dec 2018.

40. Wang X, Xu S, Zhou S, Xu W, Leary M, Choong P, Qian M, Brandt M, Xie YM. Topological design and additive manufacturing of porous metals for bone scaffolds and orthopaedic implants: a review. Biomaterials. 2016;83:127-41. https://doi.org/10.1016/J. BIOMATERIALS.2016.01.012.

41. Li X, Wang C, Zhang W, Li Y. Fabrication and compressive properties of Ti6Al4V implant with honeycomb-like structure for biomedical applications. Rapid Prototyp J. 2010;16:44-9. https://doi. org/10.1108/13552541011011703.

42. Ataee A, Li Y, Fraser D, Song G, Wen C. Anisotropic Ti-6Al-4V gyroid scaffolds manufactured by electron beam melting (EBM) for bone implant applications. Mater Des. 2018;137:345-54. https ://doi.org/10.1016/j.matdes.2017.10.040.

43. Arrieta E, Mireles J, Stewart C, Carrasco C, Wicker RB. Multiscale Analysis of cellular solids fabricated by EBM. In: Solid freeform fabrication 2017: proceedings of the 28th annual international solid freeform fabrication symposium - an additive manufacturing conference. 2017; pp 2066-2101. https://sffsymposi um.engr.utexas.edu/sites/default/files/2017/Manuscripts/Multi scaleAnalysisofCellularSolidsFabricated.pdf. Accessed 15 Dec 2018.

Publisher's Note Springer Nature remains neutral with regard to jurisdictional claims in published maps and institutional affiliations 